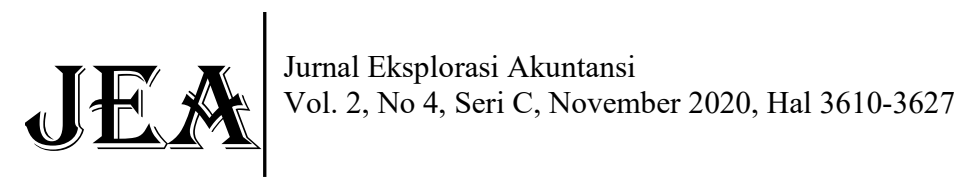

ISSN : 2656-3649 (Online)

http://jea.ppj.unp.ac.id/index.php/jea/issue/view/31

\title{
Pengaruh Jalur Pelaporan Dan Retaliasi Terhadap Niat Seseorang Melakukan Whistleblowing
} (Studi Eksperimen pada Pegawai Badan Keuangan Daerah Provinsi Sumatera Barat)

\author{
Lisa Assari ${ }^{1}$, Sany Dwita ${ }^{2}$ \\ ${ }^{1}$ Alumni Jurusan Akuntansi Fakultas Ekonomi, Universitas Negeri Padang \\ ${ }^{2}$ Jurusan Akuntansi Fakultas Ekonomi, Universitas Negeri Padang \\ *Korespondensi: lisaassari21@gmail.com
}

\begin{abstract}
This study aims to examine the effect of reporting pathways and retaliation on someone's intention to do whistleblowing. The population in this study is the Employees of the Regional Finance Agency of West Sumatra Province. The first hypothesis of this study is that individuals who deal with anonymous reporting channels will be more likely to show whistleblowing than individuals who face non-anonymous reporting pathways and the second hypothesis is individuals who face low retaliation potential will be more likely to show intention to do whistleblowing than individuals who face high retaliation potential. Experimental research with a $2 x 2$ factorial design was conducted. 80 employees of the West Sumatra province's financial services have contributed to the experiment. One Way ANOVA is used in hypothesis testing. The results showed that the reporting path did not significantly influence the intention to conduct whistleblowing with the significance value from the One Way ANOVA analysis test of 0.29>0.05. Retaliation has no significant effect on whistleblowing intentions, with the significance value of the One Way ANOVA analysis test being $0.73>0.05$.
\end{abstract}

Keywords: Repoting pathways; Retaliation; Whistleblowing

How to cite (APA $6^{\text {th }}$ style):

Assari, L \& Dwita, S. (2020). Pengaruh Jalur Pelaporan dan Retaliasi terhadap Niat Seseorang Melakukan Whistleblowing (Studi Eksperimen pada Pegawai Badan Keuangan Daerah Provinsi Sumatera Barat). Jurnal Eksplorasi Akuntansi. 2(4), Seri C. 3610-3627.

\section{PENDAHULUAN}

Whistleblowing merupakan pengungkapan atau pelaporan oleh anggota organisasi (sebelumnya atau saat ini) atas suatu tindakan ilegal, tidak bermoral, atau tidak sah dibawah kendali atasan mereka kepada individu atau organisasi yang dapat memberikan dampak tindakan perbaikan (Near dan Miceli,1985). Individu yang melaporkan atau yang melakukan whistleblowing disebut sebagai pelapor pelanggaran atau whistleblower (Near dan Miceli,1985). Seorang whistleblower dinilai sebagai orang yang dapat mendeteksi lebih cepat semua hal yang berhubungan dengan indikasi kecurangan pada instansi, sehingga peluang untuk lebih awal melakukan koreksi, mitigasi diperlukan guna mengamankan aset, reputasi serta risiko kerugian yang mungkin akan timbul (Libramawan, 2014). 
Whistleblowing dapat dibedakan menjadi dua macam yaitu whistleblowing internal dan whistleblowing eksternal (Naomi,2015). Whistleblowing internal merupakan pelaporan tindakan pelanggaran oleh anggota organisasi kepada pihak internal pemerintahan (Elias, 2008). Sedangkan whistleblowing eksternal merupakan pelaporan tindakan pelanggaran yang dilakukan oleh anggota organisasi saat pelanggaran tersebut dilakukan oleh pemerintahan kemudian dilaporkan kepada pihak eksternal dikarenakan pelanggaran itu dianggap bisa merugikan masyarakat (Elias, 2008). Penelitian terdahulu oleh (Dozier dan Miceli, 1985) menggunakan kerangka prosocial organizational behavior theory (POB) yang menjelaskan bahwa whistleblowing merupakan perilaku prososial yang menguntungkan individual, kelompok, dan organisasi.

Penelitian Putri, (2015) menguji pengaruh jalur pelaporan dan tingkat religiusitas untuk mendorong individu melaporkan pelanggaran, dari hasil penelitian menunjukkan bahwa jalur pelaporan anonymous dibawah kondisi structural model berpengaruh untuk melaporkan pelanggaran. Penelitian mengenai jalur pelaporan juga diteliti oleh Kaplan et al, (2009) dan Seifert et al, (2010) yang membuktikan bahwa seseorang akan terdorong untuk melaporkan tindak pelanggaran ketika disediakan jalur pelaporan anonymous pada kondisi structural model. Dari beberapa penelitian mengenai jalur pelaporan diatas peneliti mencoba menguji kembali dengan jalur pelaporan tanpa adanya structural model.

Melihat pentingnya whistleblowing diperlukan cara untuk mendorong keinginan seseorang mengungkap pelanggaran yang terjadi dalam organisasi (Ayers dan Kaplan, 2005). Salah satu caranya dengan menggunakan jalur pelaporan. Jalur pelaporan adalah jalur untuk seseorang dapat melaporkan kecurangan-kecurangan atau tindakan yang tidak seharusnya terjadi (Kaplan et al., 2009). Jalur pelaporan terbagi dua anonymous dan non-anonymous. Jalur pelaporan anonymous merupakan jalur pelaporan pelanggaran dimana indentitas pelapor akan dirahasiakan, sedangkan jalur pelaporan non-anonymous identitas pelapor tidak akan dirahasiakan (Kaplan et al., 2009). Regulasi ini diperlukan disebabkan kenyataan yang ada menunjukkan bahwa kasus kecurangan besar diungkap oleh para pegawai maupun media, bukan auditor sebagai pihak yang berwenang untuk mengungkapkan kecurangan (Dyck et al., 2007). Hal ini dapat ditemukan pada penelitian yang dilakukan oleh Dyck et al., (2007) yang menunjukkan media (termasuk publikasi akademik) pegawai $16,8 \%$ dan menyumbang $23,5 \%$.

Tersedianya jalur pelaporan bagi whistleblower dalam mengungkapkan pelanggaran tidak terlepas dari ancaman dan bahaya. Menurut Magnus dan Viswesveran, (2005) retaliasi suatu bentuk paksaan atau konsekuensi terhadap whistleblower untuk menutup mulut mereka saat mengetahui penipuan yang terjadi dalam suatu organisasi. Biasanya retaliasi dilakukan oleh rekan kerja atau manajer terhadap pegawai yang telah melaporkan pelanggaran (Joy, 2014). Adanya retaliasi dapat menghalangi tindakan prososial dalam organisasi yaitu whistleblowing (Hoffman, 2009). Teori yang digunakan pada retaliasi yaitu Universal Dignity Theory of Whistleblowing (UDTW) yang menjelaskan bahwa retaliasi hadir ketika individu merasa mendapatkan ancaman dan membuat individu menghindari tindakan whistleblowing (Hoffman, 2009).

Penelitian ini mengisi literatur yang berkembang dengan menyarankan pentingnya keberadaan jalur pelaporan dan retaliasi terhadap whistleblowing. Peneliti menggunakan kuasi eksperimen pada Pegawai Badan Keuangan Daerah Provinsi Sumatera Barat sebagai responden pada penelitian ini, karena Badan Keuangan Daerah merupakan salah satu instansi yang dikelola oleh pemerintah yang bertugas dalam hal pengelolaan keuangan daerah yang ada di masingmasing daerah dan provinsi sehingga rentan terjadinya tindak kecurangan. 


\section{KAJIAN TEORI DAN HIPOTESIS Whistleblowing}

Definisi formal whistleblowing adalah sebagai pengungkapan oleh anggota organisasi (sebelumnya atau saat ini) dari tidak bermoral, praktik ilegal, atau tidak sah di bawah kendali atasan mereka, kepada seseorang maupun organisasi yang mungkin akan mempengaruhi dan melakukan tindakan (Near dan Miceli, 1985). Istilah whistleblowing di Indonesia terkenal beberapa dekade terakhir (Semendawai, 2011). Berbagai macam untuk mengartikan whistleblowing, kadang bisa diartikan sebagai peniup peluit, pemukul kentongan, pengungkap fakta, dan saksi pelapor, oleh karena itu sampai sekarang belum ada kata yang sah digunakan dalam bahasa Indonesia (Semendawai, 2011). Naomi (2015) mengatakan ada dua tipe whistleblowing, yaitu:

\section{Whistleblowing Internal}

Terjadi ketika seorang pegawai menyadari penipuanyang dilakukan oleh pegawai lain atau kepala bagian, kemudian melaporkan penipuan kepada pimpinan yang lebih tinggi dalam pemerintahan. Motif yang paling utama whistleblowing adalah motif moral guna mencegah bahaya terhadap pemerintahan.

\section{Whistleblowing Eksternal}

Eksternal whistleblowing melibatkan kasus dimana seorang pekerja mengetahui penipuan pemerintahannya dan kemudian membocorkannya kepada publik atau media karena dia mengetahui bahwa penipuan akan membahayakan publik.

\section{Jalur Pelaporan}

Jalur pelaporan adalah jalur untuk seseorang dapat melaporkan kecurangan-kecurangan atau tindakan yang tidak seharusnya terjadi (Kaplan et al., 2009). Jalur pelaporan terbagi dua anonymous dan non-anonymous. Jalur pelaporan anonymous merupakan jalur pelaporan pelanggaran dimana indentitas pelapor akan disembunyikan, sedangkan jalur pelaporan nonanonymous sebaliknya. Disediakannya jalur pelaporan anonymousdiharapkan dapat memberikan rasa aman bagi pelapor sehingga pegawai dapat melaporkan kecurangan tanpa rasa takut. Menurut Kaplan et al., (2009) keefektifan dari jalur pelaporan anonymous tergantung pada (1) keinginan pegawai untuk melaporkan temuannya kepada penerima yang lebih tepat (2) tingkat dimana pegawai menemukan kecurangan atau petunjuk-petunjuk kecurangan.

Miceli et al., (2009) berspekulasi bahwa peningkatan ancaman pembalasan dapat mempengaruhi apakah pelapor melaporkan secara internal (misalnya, ke saluran pelaporan di dalam pemerintahan) atau (misalnya, ke saluran pelaporan yang tidak di bawah kendali pemerintahan). Mengenai saluran pelaporan anonymousvs non-anonymous, Ayers dan Kaplan (2005) melaporkan bahwa maksud pelaporan adalah sama. Studi ini mempertimbangkan berbagai jenis kesalahan, tidak ada situasi yang secara eksplisit menganggap di mana individu, berdasarkan faktor kontekstual tertentu, mungkin terutama ragu untuk melaporkan kesalahan (Kaplan, 2007).

\section{Retaliasi}

Retaliasi adalah bentuk paksaan atau konsekuensi bagi whistleblower untuk menutup mulut mereka ketika mengetahui penipuan dalam suatu organisasi (Magnus dan Viswesveran, 2005). Retaliasi muncul saat dua kondisi, retaliasi rendah (affiliation) dan retaliasi tinggi (penalty) (Greenberger et al., 1987; Liyanarachchi, 2009). Penalty mengacu pada konsekuensi disiplin dalam bentuk ancaman terhadap orang atau properti, tuntutan hukum, pemutusan hubungan kerja, dan 
penjara. Affiliation mengacu pada bentuk hubungan dengan orang lain di dalam atau luar organisasi, yaitu individu lainnya tunduk pada retaliasi daripada whistleblower (Greenberger et al., 1987). Misalnya, jika seseorang hilang pekerjaannya karena melakukan whistleblowing, maka ini akan menjadi retaliasi tinggi (penalty). ketika seseorang kehilangan pekerjaan yang disebabkan oleh suatu individu yang melakukan whistleblowing, maka ini disebut retaliasi rendah (affiliation) (Liyanarachchi, 2009). Literatur terdahulu mengemukakan kedua jenis retaliasi menyebabkan whistleblowing berbeda tanggapan (Greenberger et al., 1987).

\section{Prosocial Organizational Behavior (POB) Theory}

Prosocial Organizational Behavior Theory merupakan salah satu teori yang memberi dukungan terhadap niat melakukan whistleblowing. Brief dan Motowidlo (1986) menjelaskan prososial merupakan perilaku yang ditujukan kepada pelaku organisasi, kelompok, dan individu yang saling berinteraksi dan masing-masingnya berperan secara organisasi serta memiliki tujuan individu, kelompok, dan organisasi tersebut.

Dozier dan Miceli (1985) mengemukakan bahwa pertama whistleblowing pada umumnya bukan tindakan altruisme (tidak egois) murni, bahkan sebaliknya whistleblower lebih tepat dipandang sebagai suatu perilaku prososial yang dapat melibatkan motif egois (egoistis) dan tidak egoistis (altruistik) dari para individu. Kedua, benar mengusulkan bahwasannya karakteristik stabil kepribadian individu tertentu dapat membuat berinteraksi dengan persepsi situasi organisasi mereka dan dapat menuntun pada perilaku whistleblowing yang diprediksi. meskipun demikian whistleblowing dapat bermanfaat terhadap whistleblower secara individu, whistleblowing bisa dilihat sebagai perilaku prososial karena umumnya dapat bermanfaat bagi orang lain (atau organisasi) selain dari whistleblower itu sendiri (Dozier dan Miceli, 1985).

\section{Universal Dignity Theory of Whistleblowing (UDTW)}

Retaliasi sendiri menggunakan teori UDTW yang dijelaskan melalui penelitian Hoffman (2009) tentang a business ethics theory of whistleblowing: responding to the \$1 trillion question, yang menghubungkan retaliasi hadir saat individu mendapatkan ancaman sehingga membuat individu menghindari tindakan whistleblowing. Hal ini memberikan arahan untuk mengusulkan kondisi berikut ini sebagai whistleblowing yang etis. Pertama, bukti kuat atas tindakan tidak sah atau tidak etis yang dilakukan oleh suatu organisasi atau pegawainya yang dianggap melanggar martabat satu atau lebih pemangku kepentingannya yang melonggarkan ketentuan pelanggaran etika. Kedua, kurangnya pengetahuan dari dalam organisasi atas kesalahan atau kegagalan oleh organisasi untuk mengambil tindakan korektif. Dua kondisi diatas membuat whistleblowing menjadi sebuah kewajiban dan diperbolehkan.

Hoffman (2009) menyatakan jika kondisi pembenaran diatas terpenuhi, maka secara etis whistleblowing akan diungkapkan, kecuali untuk kondisi ketiga dimana seseorang akan dibebaskan secara kondisional dari kewajiban untuk melakukan whistleblowing jika seseorang memiliki alasan yang dapat dipercaya untuk yakin bahwa dengan melakukan whistleblowing seseorang akan menempatkan dirinya atau orang lain di risiko retaliasi yang serius. Teori ini menunjukkan saat seseorang ingin menghindari untuk melakukan tindakan whistleblowing jika merasa yakin dan percaya terdapat ancaman retaliasi yang hadir serta mendapatkan tempat terhadap lingkungan dirinya dan orang lain (Hoffman, 2009).

\section{Pengaruh Jalur pelaporan terhadap whisteblowing}

Penelitian terdahulu diketahui ketika whistleblower menggunakan jalur pelaporan nonanonymous dan mendapatkan retaliasi, maka intensi untuk melaporkan tindak kecurangan menjadi 
rendah, sedangkan dengan menggunakan jalur anonymous dan mendapatkan retaliasi intensi untuk melaporkan tindak kecurangan menjadi lebih kuat (Putri, 2012). Hasil ini mengkonfirmasi hasil penelitian (Kaplan et al., 2012). Akan tetapi, pada kondisi tersebut, intensi untuk melaporkan tindak kecurangan menggunakan jalur non-anonymous secara signifikan berbeda dibandingkan dengan menggunakan jalur anonymous. Hasil ini tidak mengkonfirmasi hasil penelitian (Xu dan Zeigenfuss, 2009).

Berdasarkan penjelasan diatas dapat disimpulkan bahwa, whistleblower akan melaporkan kecurangan yang terjadi dengan menggunakan jalur anonymous daripada jalur non-anonymous untuk menghindari konsekuensi yang timbul akibat pelaporan tersebut. Penjelasan tersebut mengarah kepada hipotesis pertama.

$\mathbf{H}_{1}$ : Individu yang menghadapi jalur pelaporan anonymous akan lebih cenderung menunjukkan niat melakukan whisteblowing dibandingkan individu yang menghadapi jalur pelaporan nonanonymous.

\section{Retaliasi terhadap whistleblowing}

Teori Universal Dignity Theory of Whistleblowing (UDTW) menunjukkan bahwa seseorang akan dibebaskan mengambil keputusan dari kewajiban untuk melakukan whistleblowing jika seseorang memiliki alasan yang dapat dipercaya untuk yakin bahwa dengan melakukan whistleblowing seseorang akan menempatkan dirinya atau orang lain di risiko retaliasi yang serius (Hoffman, 2009). Teori ini menggammbar bahwa seseorang akan menghindari melakukan tindakan whistleblowing jika merasa percaya dan yakin terhadap adanya ancaman retaliasi yang hadir dan mendapatkan tempat dilingkungan dirinya dan terhadap orang lain (Hoffman, 2009).

Penelitian terdahulu mengkonfirmasi potensi retaliasi terhadap whistleblowing sangat penting bagi keputusan seseorang untuk terlibat pada whistleblowing (Rocha dan Kleiner, 2005). Namun whistleblowing memiliki banyak konsekuensi dan retaliasi yang hadir di hampir semua kasus (Rocha dan Kleiner, 2005). Memahami kekuatan retaliasi, posisi seorang pegawai dan statusnya didalam sebuah organisasi juga penting (Near dan Miceli, 1995). Dengan demikian, pegawai baru dapat melihat semua bentuk retaliasi sebagai ancaman lebih bagi pegawai baru daripada pegawai yang berpengalaman dan berstatus tinggi. Sementara Magnus dan Viswesveran (2005) menemukan retaliasi berengaruh negatif terhadap niat seseorang melakukan whistleblowing.

Bukti empiris untuk whistleblower menunjukkan risiko retaliasi terbesar saat whistleblower melaporkan masalah secara internal dalam organisasi mereka atau kepada pers, dibandingkan pada lembaga pemerintah eksternal negara maupun federal (Clark, 1994). Hasil dari beberapa penelitian secara empiris bersifat campuran. Secara umum adalah retaliasi yang kuat, mengakibatkan semakin kecil kemungkinan seseorang untuk melakukan whistleblowing. Dengan demikian, potensi kekuatan retaliasi akan mempengaruhi keputusan seseorang untuk berniat melakukan whistleblowing. Penjelasan diatas mengarah kepada hipotesis kedua.

$\mathbf{H}_{2}$ : Individu yang menghadapi potensi retaliasi yang rendah akan lebih cenderung menunjukkan niat melakukan whistleblowing dibandingkan individu yang menghadapi potensi retaliasi yang tinggi.

\section{METODE PENELITIAN \\ Desain Penelitian}

Penelitian ini menggunakan pendekatan kuantitatif dan tergolong jenis penelitian kausatif, serta menggunakan data primer yang dikumpulkan melalui jenis metode penelitian kuasi eksperimen. Dimana penelitian ini bertujuan untuk melihat seberapa jauh pengaruh variabel bebas mempengaruhi variabel terikat. Kuasi eksperimen ialah suatu desain yang memiliki kelompok 
kontrol, tetapi tidak dapat berfungsi sepenuhnya untuk mengontrol variabel-variabel luar yang dapat mempengaruhi pelaksanaan eksperimen (Sugiyono, 2013). Desain ini dikembangkan untuk mengatasi kesulitan dalam menentukan kelompok kontrol dalam penelitian.

Subjek kelompok dalam penelitian kuasi eksperimen ini adalah pegawai Badan Keuangan Daerah Pemerintah Provinsi Sumatera Barat. Penelitian ini menggunakan purposive sampling dalam teknik pengambilan sampel. Partisipan dipilih berdasarkan kriteria sebagai berikut :

1. Pegawai yang telah menyelesaikan tingkat pendidikan minimal D1,

2. Pegawai yang telah memiliki masa kerja lebih dari lima tahun.

Penelitian ini bertujuan untuk mengetahui sejauh mana pengaruh jalur pelaporan anonymous dengan jalur pelaporan non-anonymous dan pengaruh tinggi atau rendahnya tingkat retaliasi terhadap niat seseorang melakukan whistleblowing melalui metode kuasi eksperimen, percobaan desain menjadi 2 X 2 faktorial. Variabel bebas terdiri dari jalur pelaporan dan retaliasi.

Tabel 1

Desain Faktorial 2X2

\begin{tabular}{|c|c|c|c|}
\hline \multicolumn{2}{|c|}{} & \multicolumn{2}{|c|}{ Jalur pelaporan } \\
\cline { 3 - 4 } \multicolumn{2}{|c|}{} & Anonymous & Non-anonymous \\
\hline \multirow{3}{*}{ Retaliasi } & Tinggi & WB 1 & WB 2 \\
\cline { 2 - 4 } & Rendah & WB 3 & WB 4 \\
\hline
\end{tabular}

Keterangan :

WB 1 : Niat melakukan whistleblowing pada jalur pelaporan anonymous dan retaliasi tinggi

WB 2 : Niat melakukan whistleblowing pada jalur pelaporan non-anonymous dan retaliasi tinggi

WB 3 : Niat melakukan whistleblowing pada jalur pelaporan anonymous dan retaliasi rendah

WB 4 : Niat melakukan whistleblowing pada jalur pelaporan non-anonymous dan retaliasi rendah

\section{Jenis dan Sumber Data}

Dalam penelitian ini menggunakan data kuantitatif. Jenis data yang diperoleh dari penelitian ini merupakan jenis data subjek. Data subjek (self report data) adalah data penelitian yang dilaporkan sendiri oleh responden secara individual atau kelompok dapat berupa sikap, opini, pengalaman/karakteristik. Respon tertulis akan menjadi salah satu dari klasifikasi yang digunakan atas data subjek selain dari respon lisan dan ekspresi. Responden memberikan tanggapan atas pertanyaan tertulis (kuesioner kasus) dalam bentuk respon tertulis yang telah diajukan peneliti.

Penelitian ini menggunakan sumber data primer. Data primer merupakan data yang diperoleh dari sumber pertama seperti perorangan atau individu. Pegawai Badan Keuangan Daerah Provinsi Sumatera Barat yang sesuai dengan kriteria merupakan sumber data primer dalam penelitian ini. 


\section{Teknik Pengumpulan Data}

Teknik pengumpulan data dalam penelitian ini dilakukan dengan membagikan secara langsung kuesioner kepada responden. Tujuannya adalah tercapainya tingkat pengembalian kuesioner (response rate) yang tinggi. Pembagian, pengisian, dan pengembalian kuesioner dilakukan di dalam ruangan kantor. Sebelum mengisi kuesioner, responden akan diberikan penjelasan umum mengenai tahapan pengisian kuesioner untuk menyeragamkan persepsi atas pertanyaan pada kuesioner. Responden dibebaskan untuk menanyakan pertanyaan atau pernyataan yang sulit dipahami.

\section{Instrumen Penelitian}

Instrumen pada penelitian ini merupakan pengadopsian dan memodifikasi dari Liyanarachchi (2011), untuk variabel niat seseorang melakukan whistleblowing. Sedangkan ilustrasi retaliasi yang membagi menjadi retaliasi tinggi dan rendah berasal dari penelitian Greenberger et al, (1987) dan ilustrasi jalur pelaporan yang membagi jalur pelaporan anonymous dan jalur pelaporan non-anonymous berasal dari penelitian Kaplan (2012).

Peneliti menyediakan penjelasan pada tiap-tiap bagian kuesioner, untuk dapat memastikan responden bisa memahami instruksi yang diberikan. Dibagian awal berisi tentang identitas responden. Informasi ini bersifat umum seperti usia, suku, daerah asal, jenis kelamin, pendidikan, jurusan pendidikan, posisi saat ini, berapa lama menjabat pada posisi tersebut, dan agama.

Instrumen penelitian ini terdiri dari empat kelompok skenario yang sama dengan perlakuan yang berbeda. Pada skenario kelompok 1 peneliti menambahkan perlakuan retaliasi tinggi dengan jalur pelaporan anonymous. Skenario kelompok 2 berisi perlakuan retaliasi tinggi dengan jalur pelaporan non-anonymous. Selanjutnya, untuk perlakuan skenario kelompok 3 berisi retaliasi rendah dengan jalur pelaporan anonymous, sedangkan skenario kelompok 4 berisi perlakuan retaliasi rendah dengan jalur pelaporan non-anonymous.

Uji manipulasi dilakukan untuk memastikan bahwa responden telah memahami skenario kasus dan manipulasi yang sudah diberikan sudah realistik dan dapat dipahami. Pengecekan manipulasi untuk retaliasi dilakukan dengan mengajukan pertanyaan: "Apakah Adi akan dimutasi ke posisi non-job, tidak akan menerima promosi jabatan, serta di anggap tidak bisa dipercaya jika melaporkan temuan pelanggaran?". Sedangkan pengecekan manipulasi untuk jalur pelporan dilakukan dengan mengajukan pertanyaan: "Apakah identitas pelapor akan dirahasiakan dilembaga pemerintahan tempat Adi bekerja?.” Responden yang dikatakan lulus uji manipulasi apabila merespon sesuai dengan kasus yang telah diberikan dengan mencentang salah satu pilihan.

Instrument ini sudah pernah diuji coba oleh peneliti terdahulu di Indonesia seperti Manafe (2015), Ahyarudin (2017) dan Liyanarachchi (2009) di New Zealand yang menguji variabel terhadap niat melakukan whistleblowing. Penelitian terdahulu yang menggunakan instrumen ini menampilkan sudut pandang/perspektif orang ketiga kepada responden berusaha untuk memberikan ilustrasi bahwa responden seolah-olah melihat dan mengetahui keadaan yang ada di lingkungan kerjanya secara langsung baik ketika menjadi karyawan baru atau lama. Sudut pandang orang ketiga ini digunakan oleh (Ponemon dan Gabhart, 1990; Arnold dan Ponemon, 1991). Oleh karena itu, peneliti menggunakan sudut pandang orang ketiga dalam skenario kuesioner penelitian ini.

\section{Prosedur Penelitian}

Peneliti akan membagi menjadi empat kelompok secara random. Responden akan menerima perlakuan yang berbeda secara acak. Kelompok 1 (retaliasi tinggi dan jalur pelaporan anonymous), kelompok 2 (retaliasi tinggi danjalur pelporan non-anonymous), kelompok 3 (retaliasi rendah dan 
jalur pelaporan anonymous), dan kelompok 4 (retaliasi rendah dan jalur pelporan non-anonymous). Matriks desain penelitian eksperimental dijelaskan ke dalam tabel 3.1. Sebelum melakukan eksperimen, terlebih dahulu peneliti akan memperkenalkan diri kepada responden. Kemudian peneliti akan memberikan penjelasan secara umum mengenai tujuan dari penelitian tersebut. Selanjutnya, peneliti akan menjelaskan tentang whistleblowing, retaliasi dan jalur pelporan. Setelah menjelaskan, peneliti akan memberikan lembaran instrument yang terdapat beberapa bagian yaitu, identitas responden, kuesioner kelompok 1, 2, 3, dan 4 dibagikan merata dan dengan jumlah seimbang. Setelah responden mengisi data identitas tersebut dengan lengkap. Peneliti selanjutnya akan membacakan instruksi untuk mengisi kuesioner baik jenis kelompok 1, 2, 3, dan 4 . Peneliti memberikan penekanan pada responden sebagai sudut pandang pihak pertama yang memberikan tanggapan tertulis dalam perannya sebagai whistleblower

\section{Variabel Penelitian dan Pengukurannya}

\section{Variabel Terikat (Y)}

Variabel terikat (dependen) adalah variabel yang menjadi akibat adanya variabel bebas atau variabel yang dipengaruhi. Variabel terikat pada penelitian ini ialah whistleblowing. Whistleblowing adalah pengungkapan atau pelaporan oleh anggota organisasi baik (sebelumnya atau saat ini) atas suatu tindakan ilegal, tidakbermoral, atau tidak sah dibawah kendali atasan mereka kepada individu atau organisasi yang dapat menimbulkan efek tindakanperbaikan. Pengukuran variabel whistleblowing dalam instrumen penelitian ini dilakukan dengan melihat pilihan jawaban responden pada kuesioner dalam skala likert 1-7 ( 1 = sangat tidak mungkin, $7=$ sangat mungkin).

\section{Variabel Bebas (X)}

Variabel bebas (independen) merupakan variabel yang diasumsikan bisa mempengaruhi perubahan dalam variabel terikat. Penelitian ini memakai dua variabel independen, yaitu :

\section{Jalur pelaporan $\left(\mathbf{X}_{1}\right)$}

Jalur pelaporan terbagi dua perlakuan yang dimanipulasi yaitu jalur pelaporan anonymous dan non-anonymous. Jalur pelaporananonymous merupakan jalur pelaporan pelanggaran dimana indentitas pelapor akan dirahasiakan, sedangkan jalur pelaporan non-anonymous identitas pelapor tidak dirahasiakan. Jalur pelaporan ini diukur dengan menggunakan skala nominal dimana jalur pelaporan anonymous diberi simbol angka 1 dan jalur pelaporan non-anonymousdiberi simbol angka 0.

\section{Retaliasi (X2)}

Retaliasi diukur dengan membagi partisipan menjadi dua perlakuan yang dimanipulasi yaitu retaliasi tinggi dan rendah.Dua skenario berbeda menjelaskan masing-masing retaliasi yang berbeda juga.Retaliasi ini diukur dengan menggunakan skala nominal dimana retaliasi tinggi diberi simbol angka 0 dan retaliasi rendah diberi simbol angka 1.

\section{Teknik Analisis Data}

\section{Uji Asumsi Klasik}

\section{a. Uji Normalitas}

Uji normalitas dilakukan untuk melihat apakah dalam variabel bebas dan terikat memiliki data yang terdistribusi secara normal atau tidak. Untuk hasil model terbaik adalah jika memiliki distribusi data yang normal atau mendekati normal. 


\section{b. Uji Homogenitas}

Uji homogenitas digunakan untuk mengetahui sama atau tidaknya varian dari beberapa sampel. Uji ini biasanya dilakukan sebagai syarat untuk menganalisis independent sample $t$ test dan ANOVA. Jika nilai siginifikansi $<0,05$ maka ditemukan varian dari dua kelompok lebih populasi data yang tidak sama. Begitu sebaliknya jika nilai signifikansi $>0,05$ maka dikatakan bahwa dua kelompok lebih populasi data sama/ homogen.

\section{Uji Hipotesis}

Pengujian hipotesis pertama dan kedua dalam penelitian ini menggunakan alat uji Analysis of Variance (ANOVA). ANOVA adalah prosedur pengolahan data yang dilakukan untuk menguji perbedaan nilai rata-rata beberapa grup (lebih dari dua). Dalam penelitian ini ANOVA akan digunakan untuk membandingkan kecenderungan individu untuk melakukan whistleblowing apabila berada pada kondisi jalur pelaporan lemah atau kuat serta retaliasi tinggi atau rendah.

\section{HASIL PENELITIAN DAN PEMBAHASAN Hasil Pengumpulan Data}

Data dalam penelitian ini dikumpulkan melalui penyebaran kuesioner skenario kepada pegawai Badan Keuangan Daerah Provinsi Sumatera Barat. Penyebaran kuesioner ini dilakukan pada hari jumat minggu ketiga bulan April, karena masih dalam masa pandemi COVID-19, peneliti tidak diizinkan untuk mengambil kuesioner yang dibagikan pada hari itu juga, peneliti baru dapat mengambil kuesioner pada 3 hari setelahnya. Jumlah kuesioner yang disebar adalah sebanyak 80 kuesioner, dari jumlah yang disebar peneliti hanya mendapat pengembalian kuesioner sebanyak 69 kuesoner.

Setelah peneliti mengumpulkan kuesioner yang telah disebar, jumlah kuesioner yang dapat dikatakan tidak lolos uji manipulasi adalah sebanyak 3 orang dari jumlah yang dikembalikan. Sebelum peneliti melakukan olah data terhadap kuesioner yang dikembalikan, peneliti terlebih dahulu melakukan pemeriksaan terhadap kelengkapan pengisisan data demografi dan kuesioner yang memenuhi kriteria. Berdasarkan kriteria yang telah ditetapkan pada penelitian ini sebanyak 2 kuesioner tidak memenuhi syarat untuk dapat dilanjutkan dalam tahap pengolahan data sehingga kuesiner tersebut tidak dipakai atau dimasukan dalam olah data. lebih jelasnya dapat dilihat pada tabel berikut.

Tabel 2

Penyebaran dan pengembalian kuesioner

\begin{tabular}{|l|l|l|}
\hline No & Keterangan & Jumlah \\
\hline 1 & Penyebaran Kuesioner skenario & $\mathbf{8 0}$ \\
\hline 2 & Kuesioner skenario yang tidak dikembalikan & 11 \\
\hline 3 & Kuesioner skenario yang dikembalikan & 69 \\
\hline 4 & Kuesioner skenario yang tidak lolos uji manipulasi & $\mathbf{3}$ \\
\hline 5 & Kuesioner skenario yang tidak memenuhi kriteria & $\mathbf{2}$ \\
\hline 6 & Kuesioner skenario yang diisi lengkap dan bisa diolah & $\mathbf{6 4}$ \\
\hline & Response Rate & $\mathbf{8 0} \%$ \\
\hline
\end{tabular}

(Sumber: data primer yang diolah, 2020)

\section{Karakteristik Partisipan}

Berikut ini merupakan karakteristik responden yang menjadi sampel dalam penelitian ini dapat dilihat pada tabel 3.

Tabel 3 
Karakteristik Demografi

\begin{tabular}{|c|c|c|c|}
\hline Data & Level & Frekuensi & $\%$ \\
\hline \multirow{3}{*}{ Usia } & $\mathbf{2 0 - 3 0}$ & 2 & 3,1 \\
\cline { 2 - 4 } & $\mathbf{3 1 - 4 0}$ & 13 & 20,3 \\
\cline { 2 - 4 } & $41-50$ & 21 & 32,8 \\
\cline { 2 - 4 } & $\mathbf{5 1 - 6 0}$ & 27 & 42,2 \\
\hline \multirow{3}{*}{ Jenis Kelamin } & $>60$ & 1 & 1,6 \\
\hline \multirow{2}{*}{ Agama } & Laki-Laki & 28 & 43,8 \\
\hline \multirow{3}{*}{ Pendidikan } & Perempuan & 36 & 56,3 \\
\cline { 2 - 4 } & Islam & 64 & 100,0 \\
\cline { 2 - 4 } & D3 & 35,9 & 35,9 \\
\cline { 2 - 4 } & $\mathrm{S1}$ & 54,7 & 54,7 \\
\hline
\end{tabular}

Sumber: data primer yang diolah, 2020)

Tabel diatas menunjukkan 64 sampel hasil karakteristik demografi dari usia, jenis kelamin, agama dan pendidikan. Karakteristik demografi untuk usia lebih dominan pada rentang usia antara 51-60 tahun dengan persentase 42,2\%, sementara jumlah sampel usia paling sedikit dalam penelitian ini adalah yang berumur 60 tahun keatas dengan persentase 1,6\%. Selanjutnya, karakteristik demografi jenis kelamin lebih dominan berjenis kelamin perempuan dengan persentase 56,3\%, sisanya berjenis kelamin laki-laki. Karakteristik demografi agama dalam penelitian ini seluruhnya beragama islam. Terakhir untuk karakterisistik demografi pendidikan lebih dominan berjenjang pendidikan S1 dengan persentase sebanyak 54,7\% dan persentasenya lebih sedikit berjenjang pendidikan S2 yaitu sebanyak 9,4\%.

Untuk melihat apakah ada pengaruh antara variabel demografi terhadap whistleblowing, peneliti juga menguji variabel demografi jenis kelamin terhadap variabel whistleblowing. Pada tabel 4 diperoleh hasil pengolahan data menggunakan Independent Sample T-Test, dimana jenis kelamin tidak memiliki pengaruh signifikan terhadap kecendrungan melakukan whistleblowing. Mean variabel jenis kelamin menunjukan nilai sebesar 5,79 untuk laki-laki dan 5,72 untuk jenis kelamin perempuan. Nilai signifikansi jenis kelamin menunjukan hasil 0,865, dimana nilai ini lebih besar dari 0,05 sehingga dapat disimpulkan bahwa jenis kelamin tidak mempengaruhi dalam melakukan whistleblowing, untuk penjelasan diatas dapat dilihat dalam tabel dibawah ini.

Tabel 4

Uji Independent Sample T-Test

\begin{tabular}{|c|c|c|c|c|c|}
\hline \multicolumn{2}{|c|}{} & N & Mean & Sig (2-tailed) \\
\hline \multirow{2}{*}{$\begin{array}{c}\text { Jenis } \\
\text { Kelamin }\end{array}$} & Whistleblowing & Laki-laki & $\mathbf{2 8}$ & $\mathbf{5 , 7 9}$ & $\mathbf{0 , 8 7}$ \\
\cline { 3 - 5 } & Perempuan & $\mathbf{3 6}$ & $\mathbf{5 , 7 2}$ & \\
\hline
\end{tabular}

(Sumber: data primer yang diolah, 2020)

\section{Analisis Statistik Deskriptif}

Analisis statistik deskriptif pada penelitian ini menunjukan gambaran data yang diteliti yaitu: Whistleblowing (Y), Jalur pelaporan (X1), dan Retaliasi (X2). Pengukuran analisis statistik 
deskriptif yang dilakukan menggunakan bantuan SPSS Windows Release 20.0. Hasil dari analisis statistik deskriptif variabel tersebut adalah.

\section{Analisis Deskriptif Whistleblowing (Y)}

Berikut ini pengujian mengenai analis deskriptif lebih lanjut secara statistik, sebelum itu diakukan pendeskripsian terhadap variabel whistleblowing. whistleblowing diukur dengan menanyakan pendapat responden atas kasus yang di sediakan dengan memberikan poin dalam skala 1-7 ( dimana 1sangat tidak melaporkan sampa dengan 7 sangat mungkin melaporkan). Untuk lebih jelasnya hasil uji statstik deskriptif untuk whistleblowing dapat dlihat pada tabel dibawah ini.

Tabel 5

Statistik Deskriptif Whistleblowing

\begin{tabular}{|c|c|c|c|}
\hline \multirow[t]{2}{*}{ Retaliasi } & \multicolumn{2}{|c|}{ Jalur Pelaporan } & \multirow[t]{2}{*}{ Total } \\
\hline & Anonymous & Non anonymous & \\
\hline Tinggi & $\begin{array}{c}\mathrm{N}=17 \\
\text { Mean=5,35 } \\
\mathrm{SD}=1,97\end{array}$ & $\begin{array}{c}\mathrm{N}=15 \\
\text { Mean }=6,07 \\
\mathrm{SD}=1,28\end{array}$ & $\begin{array}{c}\mathrm{N}=32 \\
\text { Mean=5,67 } \\
\mathrm{SD}=1,69\end{array}$ \\
\hline Rendah & $\begin{array}{c}\mathrm{N}=18 \\
\operatorname{Mean}=5,78 \\
\mathrm{SD}=1,22\end{array}$ & $\begin{array}{c}\mathrm{N}=14 \\
\operatorname{Mean}=5,86 \\
\mathrm{SD}=1,29\end{array}$ & $\begin{array}{c}\mathrm{N}=32 \\
\text { Mean=5,81 } \\
\mathrm{SD}=1,23\end{array}$ \\
\hline Total & $\begin{array}{c}\mathrm{N}=35 \\
\text { Mean=5,57 } \\
\mathrm{SD}=1,61\end{array}$ & $\begin{array}{c}\mathrm{N}=29 \\
\text { Mean=5,97 } \\
\mathrm{SD}=1,27\end{array}$ & \\
\hline
\end{tabular}

Sumber: data primer yang diolah, 2020)

Dari hasil analisis deskriptif variabel whistleblowing diatas pada variabel retaliasi dan jalur pelaporan didapatkan hasil yang berbeda. Pada kelompok yang mendapat jalur pelaporan anonymous dengan retaliasi tinggi memiliki nilai rata-rata whistleblowing sebesar 5, 35 dengan standar deviasi 1,97. Selanjutnya pada kelompok yang mendapatkan jalur pelaporan anonymous dengan retaliasi rendah didapatkan nilai rata-rata whistleblowing 5,78 dan standar deviasi sebesar 1,22. Dari rata-rata whistleblowing pada individu yang mendapatkan jalur pelaporan anonymous denga retaliasi tinggi maupun jalur pelaporan anonymous dengan realiasi rendah sangat mungkin melaporkan tindakan whistleblowing.

Kelompok yang medapatkan jalur pelaopran nonanonymous dengan retaliasi tinggi memiliki nilai rata-rata 6,07 dengan standar deviasi yaitu 1,28. Berbeda lagi dengan kelompok yang mendapatkan jalur pelapran nonanonymous dengan retaliasi rendah yang memiliki nilai ratarata sebesar 5,86 dengan standar deviasi sebesar 1,29. Dari hasil tersebut didapat kesimpulan bahwa individu yang menggunakan jalur pelaporan nonanonymous dengan retaliasi tinggi, maupun jalur pelaporan nonanonymous dengan retaliasi rendah sangat mungkin melaporkan tindakan whistleblowing.

Berdasarkan uraian di atas maka dapat dilihat perbandingan pada jalur pelaporan anonymous dengan nonanonymous, maka didapatkan nilai rata-rata yaitu 5,57 untuk anonymous dan 5,97 untuk nonanonymous. Pada hasil perbandingan tersebut disimpulkan bahwa individu yang menggunakan jalur pelaporan anonymous dan nonanonymous sama-sama sangat mungkin untuk melaporkan tindakan whistleblowing. berdasarkan hasil analisis deskriptif tersebut membuat hipotesis pertama yang menyatakan bahwa Individu yang menghadapi jalur pelaporan anonymous akan lebih cenderung menunjukkan niat melakukan whisteblowing dibandingkan individu yang menghadapi jalur pelaporan non-anonymous menjadi tidak terdukung. 
Perbandingan berikutnya retaliasi tinggi dan retaliasi rendah, dimana hasil rata-rata yaitu 5,67 untuk retaliasi tinggi dan 5,81 untuk retaliasi rendah. Perbandingan tersebut dapat disimpulkan bahwa individu yang mendapatkan retaliasi rendah dan tinggi sama-sama sangat mungkin untuk melakukan whistleblowing. Berdasarkan hasil dari peneliti membuat hipotesis kedua yaitu Individu yang menghadapi potensi retaliasi yang rendah akan cenderung menunjukkan niat melakukan whistleblowing dibandingkan individu yang menghadapi potensi retaliasi tinggi menjadi tidak terdukung.

\section{Analisis Deskriptif Jalur Pelaporan (X1) dan Retaliasi (X2)}

\section{Tabel 6}

Analisis Deskriptif Jalur Pelaporan dan Retaliasi

\begin{tabular}{|c|c|c|c|c|}
\hline & & Value Label & N & Persentase \\
\hline \multirow{2}{*}{$\begin{array}{c}\text { Jalur } \\
\text { Pelaporan }\end{array}$} & $\mathbf{1}$ & Anonymous & $\mathbf{3 5}$ & $\mathbf{5 4 , 7}$ \\
\cline { 2 - 5 } & $\mathbf{0}$ & Non-anonymous & $\mathbf{2 9}$ & $\mathbf{4 5 , 3}$ \\
\hline \multirow{3}{*}{ Retaliasi } & $\mathbf{0}$ & Total & $\mathbf{6 4}$ & $\mathbf{1 0 0}$ \\
\cline { 2 - 5 } & $\mathbf{1}$ & Renggi & $\mathbf{3 2}$ & $\mathbf{5 0}$ \\
\hline \multicolumn{2}{|c|}{ Total } & $\mathbf{3 2}$ & $\mathbf{5 0}$ \\
\hline
\end{tabular}

(Sumber: data primer yang diolah, 2020)

Berikutnya adalah analisis deskriptif jalur pelaporan, dimana anonymous diberi simbol angka 1 sedangkan non-anonymous diberi simbol angka 0 . Berikut dibawah ini dijelaskan dengan tabel. Pada tabel diatas diketahui bahwa nilai deskriptif jalur pelaporan, dimana jumlah dari anonymous adalah 35 responden atau 54,7\%, sedangkan untuk non-anonymous adalah 29 responden atau $45,3 \%$.

Variabel X2 pada penelitian ini adalah retaliasi, dimana untuk retaliasi tinggi diberi angka 0 sedangkan retaliasi rendah diberi angka 1. Berikut penjelasan pada tabel dibawah ini. Pada tabel diatas diketahui bahwa nilai deskriptif retaliasi, dimana jumlah dari retaliasi tinggis adalah 32 responden atau 50\%, sedangkan untuk retaliasi rendah adalah 32 responden atau $50 \%$.

\section{Uji Asumsi Klasik \\ Uji Normalitas}

Uji normalitas bertujuan untuk menguji apakah data variabel whistleblowing (Y), jalur pelaporan (X1), dan retaliasi X2) sudah teridistribusi normal atau tidak. Pengujian normalitas dalam penelitian ini menggunakan uji statistik Kolmogorov-Smirnov (K-S) dengan dasar pengambilan keputusan jika nilai signifikansi $>0,05$ maka data dapat dikatakan normal. Uji normalitas dilakukan dengan bantuan SPSS Windows Release 20.0. Hasil uji tersebut dapat dilihat pada Tabel 9 berikut ini:

Tabel 8

Uji Normalitas

\begin{tabular}{|c|c|c|c|c|c|c|c|c|}
\hline \multirow{2}{*}{ Jalur Pelaporan } & \multicolumn{3}{|c|}{ Kolmogorov-Smirnov } & \multicolumn{3}{|c|}{$\begin{array}{c}\text { Kolmogorov- } \\
\text { Smirnov }\end{array}$} \\
\cline { 3 - 5 } & & Statistic & df & Sig. & & Statistic & df & Sig. \\
\cline { 3 - 8 } & Anonymous & $\mathbf{0 , 2 7}$ & $\mathbf{3 5}$ & $\mathbf{0 , 0 0}$ & Tinggi & $\mathbf{0 , 3 4}$ & $\mathbf{3 2}$ & $\mathbf{0 , 0 0}$ \\
\hline & Nonanonimous & $\mathbf{0 , 3 1}$ & $\mathbf{2 9}$ & $\mathbf{0 , 0 0}$ & Rendah & $\mathbf{0 , 2 4}$ & $\mathbf{3 2}$ & $\mathbf{0 , 0 0}$ \\
\hline
\end{tabular}

(Sumber: data primer yang diolah, 2020)

Tabel diatas menunjukan nilai signifikansi Kolmogorov-Smirnov, untuk item informasi anonymous sebesar $0,00<0,05$ dan nonanonymous sebesar $0,00<0,05$. Nilai signifikansi 
Kolmogorov-Smirnov, untuk item retaliasi tinggi sebesar $0,00<0,05$ dan retaliasi rendah 0,00<0,05. Dengan demikian, hasil menunjukkan data tidak terdistribusi secara normal.

\section{Uji Homogenitas}

Uji homogenitas bertujuan untuk mengetahui tingkat kesamaan varians antara dua kelompok yaitu kelompok anonymous dan nonanonymous, serta kelompok retaliasi tinggi dan retaliasi rendah. Pengujian dilakukan dengan bantuan SPSS Windows Release 20.0, dengan cara membandingkan nilai sig pada Levene's Statistic. Kriteria pengujian homogenitas yaitu jika nilai signifikansi $>0,05$, maka dapat dikatakan bahwa varian data adalah homogen. Hasil uji homogenitas dapat dilihat pada Tabel 10 sebagai berikut:

Tabel 9

\section{Uji Homogenitas}

\begin{tabular}{|c|c|c|c|}
\hline \multicolumn{4}{|c|}{$(\mathrm{N}=64)$} \\
\hline No & Variabel & Levene Statistic & Sig. \\
\hline 1 & Jalur Pelaporan & 3,37 & $\mathbf{0 , 0 7}$ \\
\hline 2 & Retaliasi & 6,90 & $\overline{\mathbf{0 , 0 1}}$ \\
\hline
\end{tabular}

Pada Tabel diatas kolom Levene Statistic untuk variabel jalur pelaporan menunjukkan nilai 3,37 dengan nilai signifikansi sebesar 0,07. Nilai tersebut lebih besar dari 0,05, maka dapat disimpulkan bahwa antara dua kelompok yaitu informasi anonymous dan nonanonymous memiliki varian yang sama. Nilai Levene Statistic untuk variabel retaliasi yaitu 6,90 dengan nilai signifikansi sebesar 0,01 . Nilai signifikansi retaliasi lebih kecil dari 0,05 , sehingga dapat dismpulkan bahwa antara kelompok retaliasi tinggi dan retaliasi rendah tidak memiliki varian yang sama.

\section{Uji Hipotesis}

Teknik analisis data yang digunakan untuk menguji kebenaran hipotesis yang diajukan adalah dengan menggunakan analisis uji One Way ANOVA (Analysis of Variance). Analisis One Way ANOVA pada dasarnya bertujuan untuk membandingkan nilai rata-rata yang terdapat pada variabel terikat di semua kelompok yang dibandingkan. Nilai masing-masing kelompok dilihat berdasarkan pada variabel bebas yang berskala kategori. One Way ANOVA menguji secara satupersatu dari masing-masing variabel X1 atau variabel X2 terhadap Y. Berikut hasil uji hipotesis pada tabel dibawah ini.

Tabel 10

Hasil uji Parametrik dan Non-Parametrik

\begin{tabular}{|l|c|c|c|}
\hline \multicolumn{4}{|c|}{ One Way ANOVA } \\
\hline Jalur Pelaporan & Mean Square & F & Sig. \\
\hline Retaliasi & $\mathbf{0 , 2 5}$ & $\mathbf{0 , 1 1}$ & $\mathbf{0 , 7 3}$ \\
\hline \multicolumn{3}{|c|}{ Kruskal Wallis } \\
\hline \multicolumn{3}{|c|}{} & $\mathbf{1 , 1 4}$ \\
\hline Anonymous & $\mathbf{2 , 4 6}$ & $\mathbf{3 4 , 5 9}$ & \multirow{2}{*}{ Asymp.sig. } \\
\hline Non-anonymous & $\mathbf{3 0 , 7 7}$ & $\mathbf{0 , 3 8}$ \\
\hline Retaliasi tinggi & $\mathbf{3 2 , 9 7}$ & $\mathbf{0 , 8 3}$ \\
\hline Retaliasi rendah & $\mathbf{3 2 , 0 3}$ & \\
\hline
\end{tabular}

(Sumber: data primer yang diolah, 2020) 


\section{Hipotesis Pertama}

Hipotesis pertama di uji menggunakan uji One Way ANOVA. Hipotesis pertama $(\mathrm{H} 1)$ yang dirumuskan dalam penelitian ini adalah individu yang menghadapi jalur pelaporan anonymous akan lebih cenderung menunjukkan niat melakukan whisteblowing dibandingkan individu yang menghadapi jalur pelaporan non-anonymous. Pada Tabel diatas menunjukan hasil uji parametrik yang menunjukkan mean square senilai 0,25 dan nilai signifikansi uji analisis One Way ANOVA sebesar 0,29>0,05. Hal ini membuktikan bahwa individu yang menghadapi jalur pelaporan anonymous akan lebih cenderung menunjukkan niat melakukan whisteblowing dibandingkan individu yang menghadapi jalur pelaporan non-anonymous adalah salah.

Hipotesis pertama memiliki tambahan uji non-parametrik. Uji non-parametrik ini bertujuan untuk kelengkapan hasil penelitian yang yang memiliki data yang tidak berdistribusi normal. Uji non-parametrik yang digunakan adalah uji Kruskal Wallis yang bertujuan untuk uji dua kelompok atau lebih yang tidak berpasangan dengan skala ordinal atau nominal. Tabel diatas menunjukkan mean rank untuk anonymous dan nonanonymous yang berbeda yaitu mean rank anonymous lebih tinggi dari pada nonanonymous sebesar 34,59 dan 30,77. Nilai signifikansi yang ditunjukkan oleh nilai asymp.sig. yang dihasilkan adalah 0,38 dimana lebih besar dari 0,05. Dengan demikian dari hasil analisis tersebut dapat ditarik kesimpulan bahwa hipotesis pertama $\left(\mathbf{H}_{1}\right)$ tidak terdukung.

\section{Hipotesis Kedua}

Hipotesis kedua juga di uji menggunakan uji One Way ANOVA, dimana hipotesis yang dirumuskan dalam penelitian ini adalah individu yang menghadapi potensi retaliasi yang rendah akan lebih cenderung menunjukkan niat melakukan whistleblowing dibandingkan individu yang menghadapi potensi retaliasi yang tinggi. Pada Tabel diatas menunjukan hasil uji parametrik yang menunjukkan mean square senilai 2,46 dan nilai signifikansi uji analisis One Way ANOVA sebesar $0,73<0,05$. Hal ini membuktikan bahwa individu yang menghadapi potensi retaliasi yang rendah akan lebih cenderung menunjukkan niat melakukan whistleblowing dibandingkan individu yang menghadapi potensi retaliasi yang tinggi adalah salah.

Hipotesis kedua juga memiliki tambahan uji non-parametrik, dimana menunjukkan mean rank untuk retaliasi tinggi dan retaliasi rendah yang berbeda yaitu mean rank retaliasi tinggi lebih tinggi dari pada retaliasi rendah sebesar 32,97 dan 32,03. Nilai signifikansi yang ditunjukkan oleh nilai asymp.sig. yang dihasilkan adalah 0,83 dimana lebih besar dari 0,05. Dengan demikian dari hasil analisis tersebut dapat ditarik kesimpulan bahwa hipotesis kedua $\left(\mathbf{H}_{2}\right)$ tidak terdukung.

\section{Pembahasan}

\section{Pengaruh Jalur Pelaporan Terhadap Whistleblowing}

Hasil uji hipotesis menunjukan bahwa hipotesis pertama yang dirumuskan yaiu individu yang menghadapi jalur pelaporan anonymous akan lebih cenderung menunjukkan niat melakukan whisteblowing dibandingkan individu yang menghadapi jalur pelaporan nonanonymous. Berdasarkan hasil pengujian menyatakan bahwa variabel jalur pelaporan memiliki nilai signifikansi lebih besar dari 0,05 yaitu 0,29 , sehingga dapat disimpulkan bahwa jalur pelaporan tidak berpengaruh signifikan terhadap niat melakukan whistleblowing. hal ini membuktikan bahwa hipotesis pertama ditolak. Hal ini membuktikan bahwa hipotesis pertama ditolak. Hasil penelitian ini berbeda dengan hasil penelitian terdahulu yang mendapatkan jalur pelaporan anonymous akan lebih cenderung menunjukkan niat melakukan whistleblowing dibandingkan yang mendapatkan jalur pelaporan non-anonymous (Putri, 2012).

Kaplan et al., (2009) menyatakan ketika disediakannya jalur pelaporan anonymous diharapkan dapat memberikan rasa aman bagi pelapor sehingga pegawai dapat melaporkan kecurangan tanpa rasa takut. Jika dilihat pada skenario yang diberikan kepada partisipan dalam 
penelitian ini, didalamnya telah ditambahkan skenario retaliasi pada kondisi jalur pelaporan baik anonymous dan non-anonymous terhadap whistleblowing. Hal ini membuat peneliti berkesimpulan bahwa ketika individu dihadapi pada jalur pelapolaran baik anonymous dan non-anonymous akan berpengaruh ketika adanya retaliasi dan membuat individu mempertimbangkan kembali untuk mengungkapkan whistleblowing.

\section{Pengaruh Retaliasi terhadap Whistleblowing}

Hasil uji hipotesis menunjukan bahwa hipotesis pertama yang dirumuskan yaiu Individu yang menghadapi potensi retaliasi yang rendah akan lebih cenderung menunjukkan niat melakukan whistleblowing dibandingkan individu yang menghadapi potensi retaliasi yang tinggi. Berdasarkan hasil pengujian menyatakan bahwa variabel retaliasi memiliki nilai signifikansi lebih besar dari 0,05 yaitu 0,73, sehingga dapat disimpulkan bahwa retaliasi tidak berpengaruh signifikan terhadap niat melakukan whistleblowing. hal ini membuktikan bahwa hipotesis kedua ditolak.

Hasil ini tidak sejalan dengan teori Universal Dignity Theory of Whistleblowing (UDTW yang menyebutkan bahwa seseorang akan menghindari melakukan tindakan whistleblowing jika merasa yakin dan percaya ada ancaman retaliasi yang hadir dan mendapatkan tempat terhadap lingkungan dirinya dan terhadap orang lain (Hoffman, 2009). Penelitian terdahulu membuktikan potensi retaliasi terhadap whistleblowing sangatlah penting bagi keputusan seseorang yang terlibat dalam whistleblowing (Rocha dan Kleiner, 2005). Bukti empiris untuk whistleblower juga menunjukkan bahwa risiko retaliasi terbesar adalah jika whistleblower melaporkan masalah secara internal di dalam organisasi mereka atau kepada pers, dibandingkan kepada lembaga pemerintah eksternal baik negara atau federal (Clark, 1994). Sama hal nya dengan penelitian Rocha dan Kleiner, 2005, Larasati (2015) juga melakukan penelitian mengenai pengaruh retaliasi terhadap whistleblowing. Metode survei digunakan dalam penelitian ini dengan menggunakan instrumen kuesioner. Hasil penelitian ini membuktikan bahwa penalaran moral, retaliasi dan rasa bersalah memiliki pengaruh yang signifikan terhadap kecenderungan individu untuk melakukan whistleblowing.

Sejalan dengan penelitian ini, Sementara Magnus dan Viswesveran (2005), dimana juga menemukan hasil bahwa ancaman retaliasi memiliki pengaruh negatif terhadap niat melakukan whistleblowing

\section{KESIMPULAN, KETERBATASAN DAN SARAN Kesimpulan}

Berdasarkan hasil temuan penelitian dan pengujian hipotesis yang telah dilakukan dapat disimpulkan sebagai berikut (1) Individu yang menghadapi jalur pelaporan anonymous dan nonanonymous sama-sama menunjukkan niat melakukan whisteblowing. (2) Individu yang menghadapi potensi retaliasi yang rendah dan retaliasi tinggi sama-sama menunjukkan niat melakukan whistleblowing.

\section{Keterbatasan}

Dalam penelitian yang dilakukan, peneliti tidak terlepas dari adanya keterbatasan. Adapun keterbatsan yang ditemui yaitu: (1) Peneliti tidak dapat mengawasi jalanya pengisian kuesioner karena situasi dan kondisi yang tidak memungkinkan, sehingga peneliti tidak dapat memastikan apakah responden paham dengan instrumen yang diberikan. (2)Peneliti hanya berfokus pada satu instansi pemerintahan saja, sedangkan masih banyak instansi lain yang rentan terhadap kecurangan dan pelanggaran. 


\section{Saran}

Dalam penelitian yang dilakukan, peneliti tidak terlepas dari adanya keterbatasan. Adapun keterbatsan yang ditemui yaitu: (1) Peneliti selanjutnya agar dapat memperhatikan lagi waktu pengisian kuesioner sehingga dapat diawasi secara langsung. (2) Peneliti selanjutnya dapat menambah jumlah sampel yang diteliti dan populasi penelitian tidak hanya dikhususkan pada satu instansi pemerintahan saja. (3) Peneliti selanjutnya disarankan untuk memperluas objek penelitian serta yang menerapkan sistem whistleblowing untuk mendapatkan hasil yang lebih relevan.

\section{DAFTAR PUSTAKA}

Ayers, S., and S. Kaplan. (2005). Wrongdoing by consultants: An examination of employees' reporting intentions. Journal of Business Ethics, 57, 121-137.

Bhargava, N., dan Madala, M., K. (2014). An overview of whistleblowing status in various continents across the world. International journal of management and social sciences research (IJMSSR), 3(10).

Brief, A. P., dan Motowidlo, Stephan J. (1986). Prosocial Organizational Behaviors. The Academy of management review, 11(4), 710-725.

Clark, David. (1994). Whistleblowing: theory anda practice. Ajal Forum, 1.

Detik.com.(2016). Kasus Penyalahgunaan Dana Bansos. Diakses pada 04 Januari 2020.

Diani, Rury C., dan Narsa, I M. (2017). Moral Reasoning level and role conflict: experimental study for whistleblowing behavior model internal government auditors. Jurnal Tata kelola dan akuntabilitas keuangan negara, 3(2), 131-149.

Dinc, M. Sait et al. (2018). Exploring predictors of internal, external anda anonymous whistleblowing intentions: a quantitative analysis of accounting professionals. International journal of applied statistics and econometrics, 1.

Diniastri, E. 2010. Korupsi, Whistleblowing dan Etika Organisasi. Skripsi. Jurusan Akuntansi, Fakultas Ekonomi. Universitas Brawijaya. Malang.

Dozier, J. B., dan Miceli, Marcia P. (1985). Potential Predictors of Whistle-blowing: Prosocial Behavior Perspective. Academy of Management Review, 10(4), 823-836.

Dyck, A., Morse, A., \& Zingalses, L. (2007). Who blows the whistle on corporate fraud? Working paper 12882 : National Bureau of Economic Research.

Dyck, Alexander et al. (2010). Who blows the whistle on corporate fraud. The journal of finance, $\mathrm{LXV}(6)$.

Greenberger, David B. et al. (1987). Oppositions and Group Norms: The Reciprocal Influence of whistleblowers ad co- workers. Journal of business ethics, 6, 527-542.

Hendel, J. .2016. Understanding retaliation of whistleblower: under which circumstances do organizations retaliate against whistleblower?. Thesis. Copenhagen business school, $115 / 260,931$.

Hoffman, B. J. (2009). Exercises and Dimensions are the Currency of Assessment Centers. Personel Psychology, 64, 351-395.

Jarrakpos.com.(2018). Kasus Badan Pengelola Keuangan dan Aset Daerah Padangbai Karangasem. Diakses pada 4 Januari 2020.

Joy, Amy Block. (2014). Retaliation: Case study on prevention strategies. Faculty of Emeritus and Author. University Of California Davis. 
Kaplan, S., Pany, K., Samuels, J., \& Zhang, J. (2009). An examination of the effects of procedural safeguards on intentions to anonimly report fraud. Auditing: A Journal of Practice and Theory, 28. 273-288.

Kaplan, Steven E., Pany, K., Samuels, J., dan Zhang, J. (2012). An Examination of Anonimand Non-anonimFraud Reporting Channels. Advances in Accounting, Incorporating Advances in International Accounting, 28, 88-95.

Keenan, John P et al. (1992). Whistleblowing: a conceptualization and model. Academy of Management Journal, (1).

Keenan, John P. (2002). Whistleblowing: A Study of managerial differences. Employee Responsibilities and rights Journal, 14(1).

Libramawan, I P. (2014). Pengaruh Penerapan Whistleblowing System Terhadap Pencegahan Kecurangan. Skripsi, Universitas Widyatama.

Liputan6.com. (2005). Kasus Parmalat. Diakses pada 06 Oktober 2020.

Liyanarachchi, G. A., and Adler, R. (2011). Accountants' whistleblowing intentions: The Impact of retaliation, age, and gender. Australian Accounting Review, 21(2), 167-182.

Liyanarachchi, G., dan Newdick C. (2009). The Impact of Moral Reasoning and Retaliation on Whistle Blowing: New Zealand Evindence. Journal of Business Ethics, 89, 37-57.

Magnus, Mesmer., dan Viswesvaran, C. (2005). Whistleblowing in Organizations: An Examination of Correlates of Whistleblowing Intentions, Actions, and Retaliation. Journal of Business Ethics, 62, 277-297.

Miceli, M., Near, J., \& Dworkin, T. (2009). A word to the wise: how managers and policy makers can encourage employees to report wrongdoing. Journal of Business Ethics, 86(3), 379396.

Miceli, Marcia P et al. (1999). Can Laws protect whistleblowers? Result of a naturally occurring field experiment. Work and Occupations, 26(1), 129-151.

Naomi, Sharon. 2015. Penerapan Whistleblowing System dan dampaknya terhadap fraud. Skripsi. Fakultas Ekonomi dan Bisnis. Universitas Lampung. Bandar Lampung.

Near, J. P., dan M. P. Miceli. (1985). Organizational Dissidence: The Case of WhistleBlowing. Journal of Business Ethics, 4(1). 1-6.

Near, J.P., dan Miceli, Marcia P. (1986). Retaliation against whistleblower: predictors and effects. Journal of Applied Psychology, 71(1), 137-145.

O'Leary, Conor., dan Derry Cotter. (2000). The ethics of final year accountancy students: an international comparison. Managerial auditing journal, 15(3), 108-115.

Parmerlee, Marcia A et al. (1982). Correlations of Whistleblowers' Perceptions of Organizational Retaliation. Adminitrative Science Quarterly, 27(1). 17-34.

Penner, Louis A et al. (1995). Measuring The Prosocial Personality.University of South Florida.

Ponemon, L. and D. Gabhart. (1990). Auditor Indepen- dence Judgements: A CognitiveDevelopment Model and Experimental Evidence. Contemporary Accounting Research 7(Fall), 227-251.

Putri, C. M. (2012). Pengujian Keefektifan Jalur Pelaporan Pada Structural Model Dan Reward Model Dalam Mendorong Whistleblowing: Pendekatan Eksperimen. Simposium Nasional Akuntansi XV, Banjarmasin, 097.

Putri, C. M. (2015). Pengaruh Jalur Pelaporan dan Tingkat Religiusitas terhadap Niat Seseorang Melakukan Whistleblowing. Jurnal Akuntansi dan Inveatasi, 17(1), 22 - 52.

Rocha, E., dan Kleiner, B. H. (2005). To Blow or Not to Blow the Whistle? That is the Question. Management Research News, 28(11/12), 80-87. 
Scholtens, M. T. (2003). Review of the Operation of the Protected Disclosures Act 2000: Report to the Minister of State Services.

Seifert, D.L., Sweeney, J. T., Joireman, J., dan Thornton, J,M. (2010). The influence of organizational justice on accountant whistleblowing. Accounting, Organization, and Society, 35, 707-717.

Sekaran, Uma. (2003). Research Methods for Business, A Skill-Building Approach. Fourth Edition. United State of America: John Wiley \& Sons inc.

Sekaran, Uma. (2006). Metode Penelitian Bisnis, Salemba Empat, Jakarta.

Semendawai, Abdul Haris, dkk. (2011). Memahami Whistleblower. Lembaga Perlindungan Saksi dan Korban (LPSK). Diakses pada 13 Desember 2019 dari www.lpsk.go.id.

Sugiyono. (2013). Metode Penelitian Kuantitatif, Kualitatif dan R \& D. Bandung: Alfabeta.

Transparancy International. (2018). Corruption Perception Index Indonesia. Diakses pada 10 Desember 2019 dari https://www.transparency.org/.

Tribunnews.com.(2010). Kasus Gayus Tambunan. Diakses 06 Oktober 2020.

Undang-undang No. 20 Tahun 2001 tentang Pemberantasan Tindak Pidana Korupsi.

Wikipedia.org. (2018). HIH Insurance Collapse. Diakses pada 06 Oktober 2020 dari https://en.wikipedia.org/.

Wordpress.com. (2011). Skandal akuntansi Worldcom. Diakses pada 06 Oktober 2020.

$\mathrm{Xu}$, Y., dan Ziegenfuss, D. (2008). Reward systems, moral reasoning, andinternal auditors' reporting pelanggaran. Journal of Business Psychology, 22, 323-331.

Zhuang, Jinyun et al. (2005). Examining culture's effect on whistleblowing and peer reporting. Business and society, 44(4). 462-486. 